\title{
Salicylic acid-mediated alleviation of cadmium toxicity in maize leaves
}

\author{
Khalid Al-Mureish, Nasim Abdual Rahim Mohammed Othman, \\ Abdulbasset Mohammed Ahmed Al-Hakimi*
}

Department of Biology, Faculty of Applied Science, Taiz University, Taiz, Yemen

Email address:

alhakimi1969@yahoo.com (A. M. A. Al-Hakimi)

\section{To cite this article:}

Khalid Al-Mureish, Nasim Abdual Rahim Mohammed Othman, Abdulbasset Mohammed Ahmed Al-Hakimi. Salicylic Acid-Mediated Alleviation of Cadmium Toxicity in Maize Leaves. Journal of Plant Sciences. Vol. 2, No. 6, 2014, pp. 276-281.

doi: $10.11648 /$ j.jps.20140206.13

\begin{abstract}
The present study was carried out to investigate the effects of salicylic acid (SA) pretreatment on the activities of antioxidant enzymes and some biochemical attributes in maize (Zea mays L.) seedling leaves exposed to cadmium (Cd) stress. The $\mathrm{Cd}$ toxicity in maize leaves was revealed by reduction of ascorbate and cysteine concentrations. However, a remarkable increase of such non-enzymatic antioxidants concentrations was noticed on the pretreatment with SA. Cadmium- induced oxidative stress also showed a pronounced increase in hydrogen peroxide $\left(\mathrm{H}_{2} \mathrm{O}_{2}\right)$, lipid peroxidation, electrolyte leakage $(\mathrm{El})$ and proline production. The important point to be emphasized here is that the pretreatment with SA attenuated the adverse effects of $\mathrm{Cd}$ on these attributes. Cadmium-induced activities of some key antioxidant enzymes, peroxidase (POD) and ascorbate peroxidase (APX) was further increased on the exposure to SA. While the lower catalase (CAT) activity dues to Cd toxicity was increased by SA pretreatment.
\end{abstract}

Keywords: Antioxidants, Cadmium, Hydrogen Peroxide, Lipid Peroxidation, Salicylic Acid, Zea mays L.

\section{Introduction}

Maize (Zea mays L.) is one of the important cereals grown in most countries in the world with total areas exceeding 160 million ha. Maize producers want to buy quality seeds, because of it profound influence on the yield of maize [1].

Cadmium is a highly toxic trace element that enters the environment mainly from industrial processes and phosphate fertilizers and negatively affects plant growth and development. High $\mathrm{Cd}$ levels in plants can cause oxidative stress by producing reactive oxygen species (ROS) [2] that react with lipids, proteins, pigments and nucleic acid and cause lipid peroxidation, membrane damage and inactivation of enzymes, thus resulting toxic effects. To minimize and / or to protect against the toxic effects of these damaging ROS, plants evolve highly regulated enzymatic and non-enzymatic mechanisms to keep a balance between ROS production and destruction in order to maintain cellular redox homeostasis. Plants utilize enzymes like APX, POD and CAT as well as low molecular weight antioxidants like ascorbate (ASA) and glutathione (GSH) to scavenge ROS [3].

Interestingly, SA acts as a potential non-enzymatic antioxidant and a plant growth regulator, which influences a range of diverse physiological processes and promotes the plant resistance to biotic and abiotic stresses [4]. Recently, it has been reported that exogenous SA ameliorates the damaging effects of heavy metals in maize [5], drought stress in soybean [6] and salt stress in wheat [7].

The present work was devoted to show the changes of the antioxidant system in response to $\mathrm{Cd}$ toxicity and the effect of SA pretreatment on maize leaves. The antioxidant status was monitored through analyzing the enzymatic and non-enzymatic antioxidants and determining the lipid peroxidation, $\mathrm{H}_{2} \mathrm{O}_{2}$ levels, electrolyte leakage and proline content. In addition, this work provided clear evidences for SA protective interference action and regulation of oxidative stress caused by $\mathrm{Cd}$ toxicity in maize seedling leaves.

\section{Materials and Methods}

\subsection{Plant Materials and Treatments}

Maize seeds (Zea mays L.) were surface sterilized with 5\% sodium hypochlorite solution for 5 minutes and washed thoroughly with distilled water. The seeds were then divided into two halves. One half of the seeds were soaked in $500 \mu \mathrm{M}$ 
SA solution for 6 hours, while the other half was soaked in water. Both groups were then allowed to germinate on moist filler paper in the dark. Three-day-old, dark-grown seedlings were transplanted to a polyethylene post containing a continuously aerated full strength Hoagland's nutrient solution. The nutrient solution was aerated twice a day, and changed three times a week. $\mathrm{CdCl}_{2}$ was added into the nutrient solution at 50 and $100 \mu \mathrm{M}$. The plants grew under controlled environmental conditions. Five replicates were maintained for each treatment concentration. After 14 days of growth, i.e. 3 days after soaking the plants were harvested for analyses.

\subsection{Determination of Hydrogen Peroxide}

The hydrogen peroxide content was determined according to [8]. A $500 \mathrm{mg}$ leaf tissue was homogenized with $5 \mathrm{ml}$ of $0.1 \%$ (w/v) trichloroacetic acid (TCA). The extract was centrifuged at 12,000 rpm for 15 minutes. A 0.5- ml supernatant was added to $0.5 \mathrm{ml}$ of $10 \mathrm{mM}$ potassium phosphate buffer $(\mathrm{pH} 7.0)$ and 1 $\mathrm{ml}$ of $1 \mathrm{M}$ potassium iodide (KI) solution. The absorbance of the supernatant was measured at a wavelength of $390 \mathrm{~nm}$.

\subsection{Determination of Lipid Peroxidation}

Lipid peroxidation was determined by measuring malondialdehyde (MDA) formation according to the method described in [9]. Leaves $(500 \mathrm{mg})$ were homogenized with $2.5 \mathrm{ml}$ of $0.1 \%$ TCA solution. The extract was centrifuged at $10,000 \mathrm{rpm}$ for 10 minutes. A 4- ml $20 \%$ TCA solution containing $0.5 \%$ thiobarbituric acid (TBA) was added to every $1 \mathrm{ml}$ of the aliquot. After properly treating the mixture, it was centrifuged at $10,000 \mathrm{rpm}$ for 15 minutes, and the absorbance of the supernatant was measured at a wavelength of $532 \mathrm{~nm}$. The level of lipid peroxidation was expressed as $\mu \mathrm{mol}$ of MAD formed using an extinction coefficient of 155 $\mathrm{mM}^{-1} \mathrm{~cm}^{-1}$.

\subsection{Determination of Electrolyte Leakage}

Electrolyte leakage is used to assess the membrane permeability. Twenty leaf discs were put in a boiling tube containing $10 \mathrm{ml}$ deionized water and electrical conductivity was measured $\left(\mathrm{EC}_{\mathrm{o}}\right)$. The contents were healed at 50 and $60{ }^{\circ} \mathrm{C}$ for 25 minutes in a water bath and $\mathrm{EC}$ was measured $\left(\mathrm{EC}_{1}\right)$. Later, the contents were boiled for 10 minutes and the $\mathrm{EC}$ was again recorded $\left(\mathrm{EC}_{2}\right)$.The electrolyte leakage was calculated using the formula:

Electrolyte leakage $(\%)=\left(\mathrm{EC}_{1}-\mathrm{EC}_{\mathrm{o}}\right) /\left(\mathrm{EC}_{2}-\mathrm{EC}_{\mathrm{o}}\right) \times 100$.

\subsection{Assay of Enzymatic Antioxidants}

Catalase activity was measured by monitoring the destruction of $\mathrm{H}_{2} \mathrm{O}_{2}$ [10]. The reaction mixture consisted of $200 \mathrm{mM}$ sodium phosphate buffer ( $\mathrm{pH} 7.0$ ), $10 \mathrm{mM} \mathrm{H}_{2} \mathrm{O}_{2}, 0.05$ $\mathrm{ml}$ enzyme extract. The decrease in absorbance due to the decomposition of $\mathrm{H}_{2} \mathrm{O}_{2}$ was recorded at a wavelength of 240 $\mathrm{nm}$. The activity was calculated using the extinction coefficient $\left(\varepsilon 40 \mathrm{mM}^{-1} \mathrm{~cm}^{-1}\right)$ and expressed in $\mu$ mole of $\mathrm{H}_{2} \mathrm{O}_{2}$ $\mathrm{min}^{-1} \mathrm{mg}^{-1}$ protein. The POD activity was determined based on guaiacol oxidation [11]. The reaction mixture contained of 50 $\mathrm{mM}$ guaiacol, $10 \mathrm{mM} \mathrm{H}_{2} \mathrm{O}_{2}$ and $0.05 \mathrm{ml}$ enzyme extract. The increase in absorbance due to formation of tetraguaiacol was monitored at $470 \mathrm{~nm}$. The activity was calculated using the extinction coefficient of $26.6 \mathrm{mM}^{-1} \mathrm{~cm}^{-1}$ and expressed as $\mu \mathrm{mol}$ of $\mathrm{H}_{2} \mathrm{O}_{2} \mathrm{~min}^{-1} \mathrm{mg}^{-1}$ protein. The APX activity was determined according to [12]. APX was assayed in $3 \mathrm{ml}$ reaction mixture containing $50 \mathrm{mM}$ phosphate buffer ( $\mathrm{pH} 7.0$ ), $0.5 \mathrm{mM}$ ascorbate and $0.5 \mathrm{mM} \mathrm{H}_{2} \mathrm{O}_{2}$, the reaction was started with addition $\mathrm{H}_{2} \mathrm{O}_{2}$. APX activity was calculated as the decrease in $\mathrm{A}_{290 \mathrm{~nm}}$ of ascorbate using an extinction of 2.8 $\mathrm{mM}^{-1} \mathrm{~cm}^{-1}$. APX activity was expressed as $\mu \mathrm{mol}$ of $\mathrm{H}_{2} \mathrm{O}_{2}$ $\mathrm{min}^{-1} \mathrm{mg}^{-1}$ protein, taking into consideration that $1.0 \mathrm{~mol}$ of ascorbate is required for the reduction of $1.0 \mathrm{~mol}$ of $\mathrm{H}_{2} \mathrm{O}_{2}$.

\subsection{Determination of Soluble Protein}

To estimate soluble proteins, leaf samples $(100 \mathrm{mg})$ were boiled in $10 \mathrm{ml}$ distilled water for 2 hours. After cooling, the water extract was centrifuged at $6000 \mathrm{rpm}$, the supernatant was decanted and made up to a definite volume by distilled water and the soluble proteins were determined according to [13].

\subsection{Assay of Ascorbate Concentrations}

Ascorbate was estimated according to [14]. Leaf tissues $(100 \mathrm{mg})$ were homogenized in $5 \%(\mathrm{w} / \mathrm{v})$ sulfosalicylic acid, and were then centrifuged at $10,000 \mathrm{rpm}$ for 10 minutes. The reaction mixture for ascorbate consisted of $2 \mathrm{ml} 2 \%$ sodium

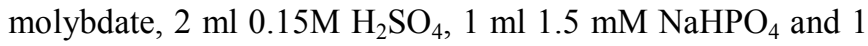
$\mathrm{ml}$ tissue extract. It was incubated in water bath at $60^{\circ} \mathrm{C}$ for 40 minutes, cooled and centrifuged at $3000 \mathrm{rpm}$ for 10 minutes, and the absorbance was measured at $660 \mathrm{~nm}$. A standard curve with ascorbate was used and calculated as $\mu \mathrm{g} \mathrm{mg} \mathrm{m}^{-1}$ of fresh leaf weight.

\subsection{Assay of Cysteine Concentrations}

Cysteine was estimated as described in [15]. Leaf tissues $(100 \mathrm{mg})$ were homogenized in $5 \%$ chilled perchloric acid and centrifuged at $10,000 \mathrm{rpm}$ for 10 minutes at $4{ }^{\circ} \mathrm{C}$. Cysteine content was measured in supernatant using acid ninhydrin reagent at $560 \mathrm{~nm}$. A standard curve with cysteine was used and calculated as $\mu \mathrm{g} \mathrm{mg}^{-1}$ of fresh leaf weight.

\subsection{Determination of Proline}

Proline concentration in the leaves was determined spectrophotometerically as described in [16]. Fresh leaf material (300 mg each sample) was ground in $10 \mathrm{ml}$ of $3 \%$ aqueous sulfosalicylic acid. The supernatant obtained after centrifugation at 12,000 rpm for 15 minutes was mixed with an equal volume of acetic acid and acid ninhydrin and incubated for 1 hour at $100{ }^{\circ} \mathrm{C}$. The chromatophore containing toluene was then aspirated from the aqueous phase, and its absorbance read spectrophotometrically at $520 \mathrm{~nm}$ using toluene as a blank. Proline content was expressed in $\mu \mathrm{M} \mathrm{g}^{-1}$ of fresh leaf weight. 


\subsection{Statistical Analysis}

Data were statistically analyzed in experimental observations wherever required, and the results were expressed as meant $\pm \mathrm{SD}$ of five independent replicates of each independent experiment. The significance of differences between control and each treatment was analyzed using analysis of variance at $P<0.05$ level of significance.

\section{Results}

Hydrogen peroxide content in maize leaves showed approximately $52.3 \%$ and $114.7 \%$ rise at 50 and $100 \mu \mathrm{M} \mathrm{Cd}$, respectively (Fig. 1A). However, exogenously applied SA caused a substantial decrease of $57.5 \%$ and $47.7 \%$ at the same concentrations of Cd (Fig. 1A). Pretreatment of SA alone also decreased $\mathrm{H}_{2} \mathrm{O}_{2}$ content by $32.2 \%$ compared with control (Fig. 1A).

Malondialdehyde (MDA) level was used as an indicator for lipid peroxidation and represents a balance of oxidative stress that induced production of MDA in relation to $\mathrm{Cd}$ treatments. Thus, MDA can be regarded as a sink for oxidative radicals. However, the results given in Fig. 1B showed a remarkable increase in MDA level as a result of $\mathrm{Cd}$ treatment. This is an indicative of the enhanced lipid peroxidation degree with increasing $\mathrm{Cd}$ concentration. The maximum increase in MDA was $52.6 \%$ and $78.5 \%$ at 50 and $100 \mu \mathrm{M} \mathrm{Cd}$, respectively. SA treatment significantly decreased MDA level compared with $\mathrm{Cd}$ treated levels (Fig. 1B). The maximum decrease in MDA by SA treatment reached $48.9 \%$ at $50 \mu \mathrm{M} \mathrm{Cd}$ and $30.8 \%$ at 100 $\mu \mathrm{M} \mathrm{Cd}$. Alone treatment with SA as well significantly decreased MDA level by $37.0 \%$.

Electrolyte leakage was increased with increasing $\mathrm{Cd}$ concentration. This increase was approximately estimated to be $66.4 \%$ and $79.3 \%$ at 50 and $100 \mu \mathrm{M} \mathrm{Cd}$, respectively compared to the control (Fig. 1C). Generally, SA pretreatment thus showed antagonizing partially or completely for the stimulatory effects of Cd toxicity on electrolyte leakage (Fig. 1C).

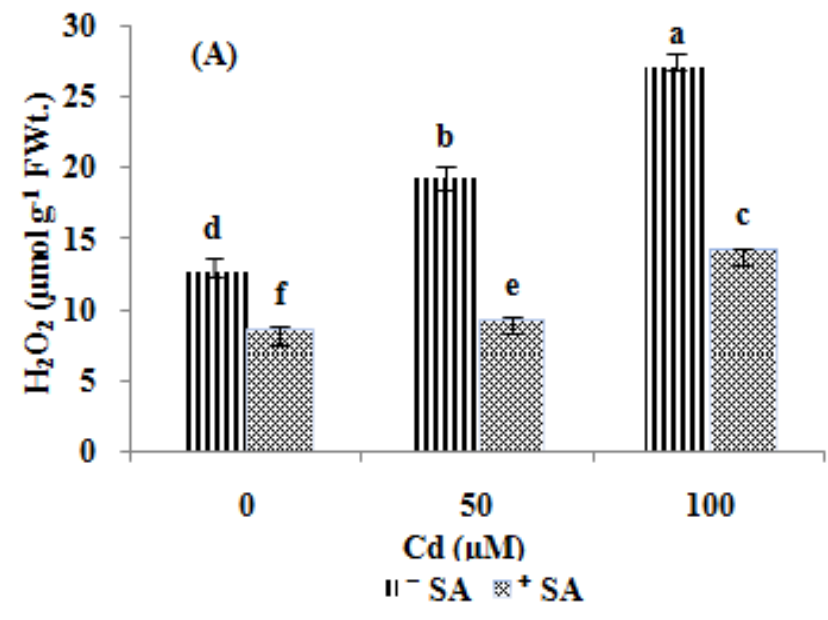

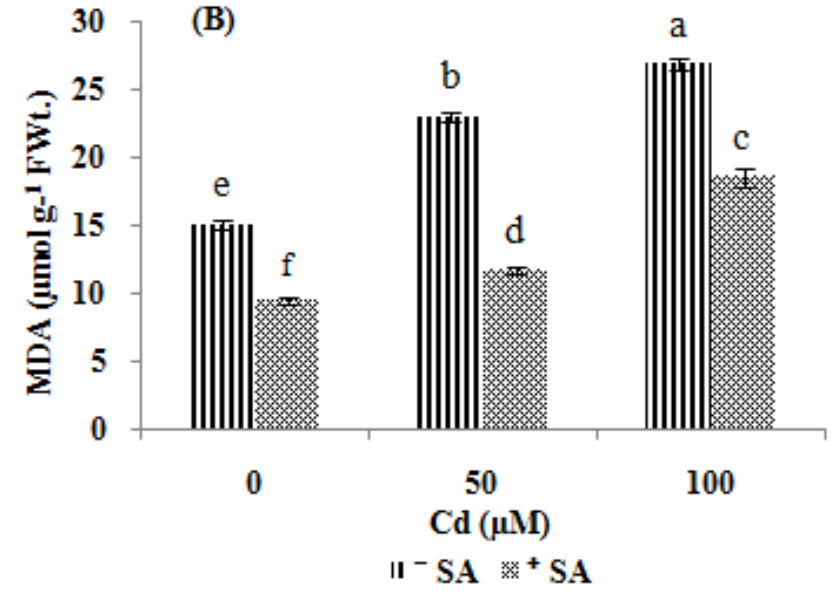

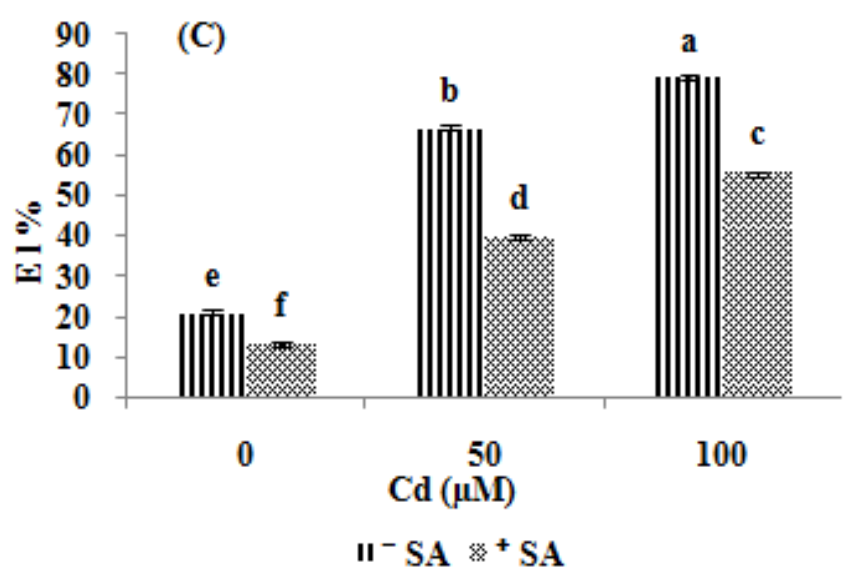

Figure 1. The action of $S A$ treatment in ameliorating the adverse effects of $C d$ toxicity on (A) $\mathrm{H}_{2} \mathrm{O}_{2},(B) M D A$ and (C) EI in leaves of maize seedlings. Values shown are the mean $\pm S D(n=5)$. Different litters indicate significantly different values at $p<0.05$.

Exposure of Cd decreased CAT activity in leaves maize by approximately $53.2 \%$ and $63.6 \%$ at 50 and $100 \mu \mathrm{M} \mathrm{Cd}$, respectively compared with control (Fig. 2A). SA pretreatment alone also decreased CAT activity by $43.5 \%$. However, SA pretreatment significantly increased CAT activity in Cd-stressed maize leaves compared with that of $\mathrm{Cd}$ alone treatment (Fig. 2A). The activity of CAT increased by $76.6 \%$ and $102.2 \%$ at 50 and $100 \mu \mathrm{M} \mathrm{Cd}$, respectively.

A significant increase in POD activity was observed in response to Cd stress (Fig. 2B). Cd- stressed leaves showed approximately $48.1 \%$ and $189.6 \%$ rise at 50 and $100 \mu \mathrm{M} \mathrm{Cd}$, respectively. SA pretreatment initially increased POD activity in leaves maize by $31.5 \%$ and $17.0 \%$ at 50 and $100 \mu \mathrm{M} \mathrm{Cd}$, respectively. SA alone also increased POD activity by $48.1 \%$.

Significant increase in the APX activity was noticed in response to Cd application (Fig. 2C). For instance, doses of 50 and $100 \mu \mathrm{M} \mathrm{Cd}$ increased the APX activity by $25.3 \%$ and $55.2 \%$, respectively. Application of SA also increased the APX activity by $15.3 \%$ and $27.0 \%$ at 50 and $100 \mu \mathrm{M} \mathrm{Cd}$, respectively (Fig. 2C). SA alone significantly increased APX activity. 

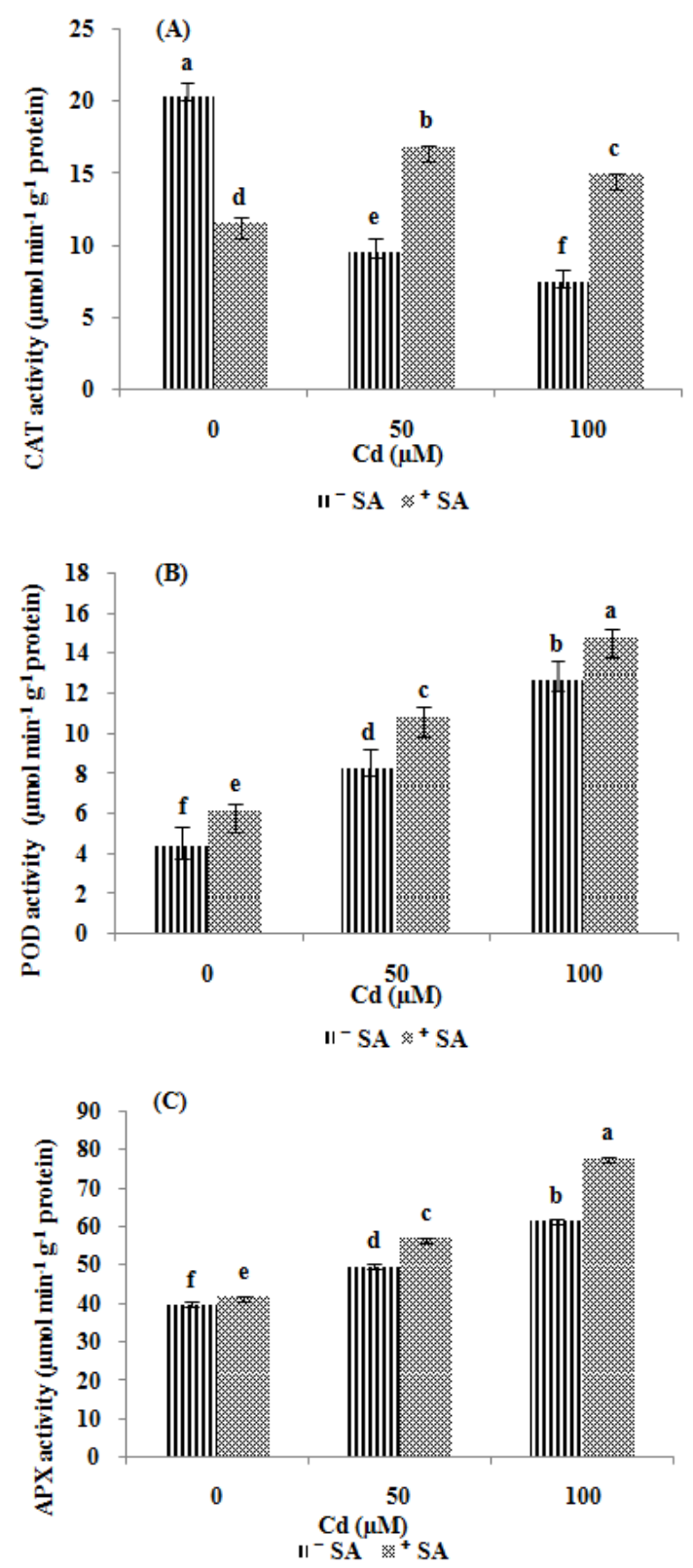

Figure 2. The action of $S$ ) treatment in ameliorating the adverse effects of $C d$ toxicity on (A) CAT, (B) POD and (C) APX activity in leaves of maize seedlings. Values shown are the mean $\pm S D(n=5)$. Different litters indicate significantly different values at $p<0.05$.

Ascorbate content was markedly decreased by Cd stress. The decrease in ascorbate induced by $\mathrm{Cd}$ treatment was found to be $36.5 \%$ and $52.4 \%$ at 50 and $100 \mu \mathrm{M} \mathrm{Cd}$, respectively. The adverse effects of $\mathrm{Cd}$ treatment on ascorbate content in leaves maize was partially by soaking seeds in SA (Fig. 3A). The ameliorative effects of SA on $\mathrm{Cd}$ induced reduction in ascorbate content were $49.8 \%$ and $43.0 \%$ at 50 and $100 \mu \mathrm{M}$ $\mathrm{Cd}$, respectively. SA alone significantly decreased ascorbate content by $17.2 \%$.

The addition of $\mathrm{Cd}$ consistently decreased cysteine content in leaves maize in all treatments (Fig. 3B). The maximum reduction in cysteine content was $23.1 \%$ and $42.5 \%$ of control at 50 and $100 \mu \mathrm{M} \mathrm{Cd}$, respectively. Pretreatment with SA initially increased cysteine content in leaves maize by $104.9 \%$

and $57.6 \%$ prior to 50 and $100 \mu \mathrm{M} \mathrm{Cd}$ treatment (Fig. 3B). SA alone significantly increased cysteine content by $61.0 \%$.
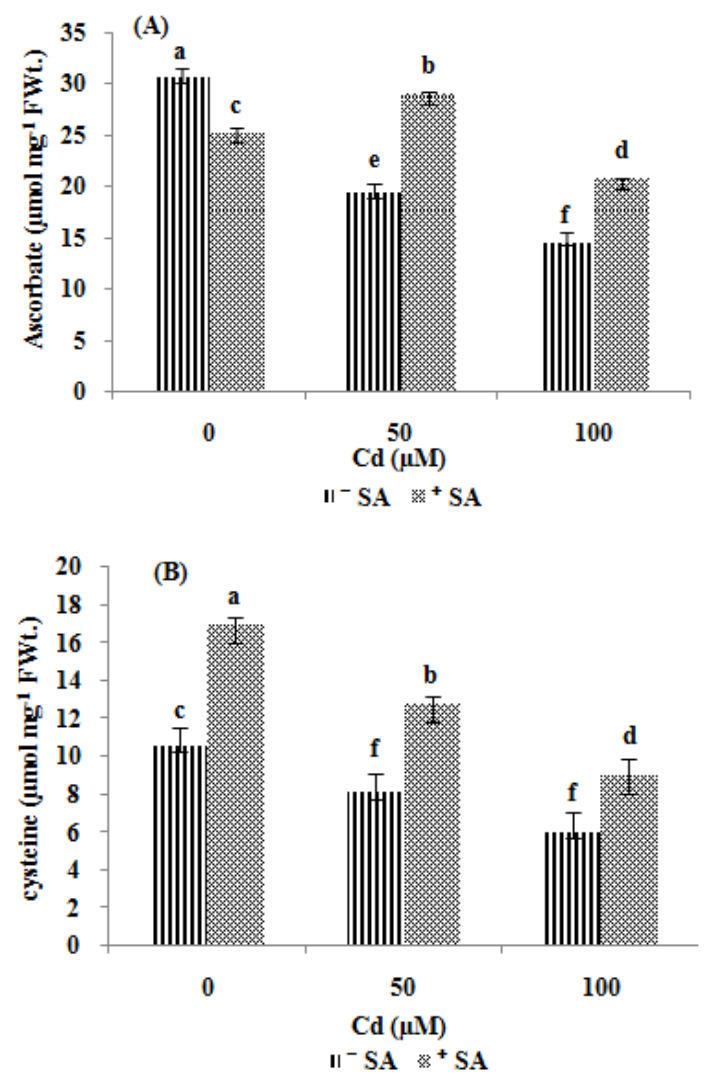

Figure 3. The action of $S A$ treatment in ameliorating the adverse effects of $C d$ toxicity on (A) ascorbate and (B) cysteine content in leaves of maize seedlings. Values shown are the mean $\pm S D(n=5)$. Different litters indicate significantly different values at $p<0.05$.

$\mathrm{Cd}$ exposure increased proline content in leaves maize by $38.5 \%$ at $50 \mu \mathrm{M}$ and $85.0 \%$ at $100 \mu \mathrm{M} \mathrm{Cd}$ compared with control (Fig. 4). Under $\mathrm{Cd}$ toxicity, SA pretreatment significantly decreased proline content compared with corresponding $\mathrm{Cd}$ alone treatment (by $42.1 \%$ and $50.0 \%$ at 50 and $100 \mu \mathrm{M} \mathrm{Cd}$, respectively (Fig. 4). SA alone also reduced the proline content by $24.4 \%$.

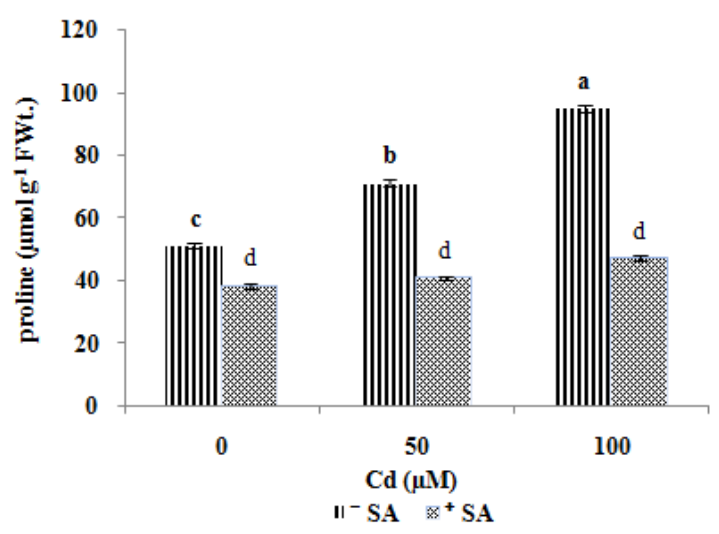

Figure 4. The action of $S A$ treatment in ameliorating the adverse effects of $C d$ toxicity on proline content in leaves of maize seedlings. Values shown are the mean $\pm S D(n=5)$. Different litters indicate significantly different values at $p$ $<0.05$. 


\section{Discussion}

Hydrogen peroxide plays significant signals for the induction and regulation of stress enzymes such as APX [17]. In the present study, the exposure to $\mathrm{Cd}$ levels in the growth medium resulted in the increase of $\mathrm{H}_{2} \mathrm{O}_{2}$ level in maize leaves. It has been found that the increase of $\mathrm{H}_{2} \mathrm{O}_{2}$ production in wheat plants is associated with the activation of the ROS-producing enzymes and the inactivation of antioxidant enzymes [18]. The enhanced $\mathrm{H}_{2} \mathrm{O}_{2}$ levels detected in $\mathrm{Cd}$-treated leaves should be indirectly originated from a decreased $\mathrm{H}_{2} \mathrm{O}_{2}$-scavenging rate and / or an increased $\mathrm{H}_{2} \mathrm{O}_{2}$ production by cell enzymatic and non-enzymatic processes. In any case, the production of $\mathrm{H}_{2} \mathrm{O}_{2}$ may be involved in the integration of cellular processes and in the adaptation to environmental stimuli [19], since, for instance, $\mathrm{H}_{2} \mathrm{O}_{2}$ is required for cross-linking cell wall components and for regulating gene expression associated with antioxidant defense [20]. In general, the applied SA has partially or completely antagonizing for the stimulatory effect of $\mathrm{Cd}$ toxicity on $\mathrm{H}_{2} \mathrm{O}_{2}$ level. The lowering in $\mathrm{H}_{2} \mathrm{O}_{2}$ levels under SA pretreatment is without doubt attributed to the increased activities of CAT and APX as a response to SA exposure.

Cadmium is not a redox active metal; nevertheless, it can indirectly generate ROS that can cause oxidative damage to cellular constituents including lipids. MDA is one of the end products which are produced as a result of lipid production damage by free radicals. Lipid production level as indicated by accumulated MDA. MDA increases significantly under $\mathrm{Cd}$ stress. This suggests that the $\mathrm{Cd}$ stress induced membrane injury, which may be due to changes in the membrane lipids or protein or both $[21,22,23]$. The applied SA has partially or completely antagonizing for the stimulatory effect of Cd stress on MDA level of maize leaves. However, SA decreases the content of lipid peroxidation by inhibiting production of hydroxyl radical [22]. The beneficial effect of SA could be attributed to modified compartmentalization, and increased activities of defense mechanisms such as antioxidant enzymes which could be involved in lowering Cd toxicity [24].

Like MDA, the electrolyte leakage also increased significantly under both two $\mathrm{Cd}$ concentrations. This confirmed that $\mathrm{Cd}$ toxicity in leaf maize was linked to free radical processes in membrane components leading to alterations in membrane stability and increasing their permeability [21, 23]. The applied SA was generally effective in antagonizing partially or completely for the stimulatory effect of $\mathrm{Cd}$ stress on electrolyte leakage. The remarkable decrease in electrolyte leakage is a clear evidence for the reduction of membrane damage, increased membrane stability and high tolerance of plants under SA pretreatment [5, 22]. In one hand, CAT activity markedly decreased in maize seedling leaves with $\mathrm{Cd}$ toxicity. The decrease in CAT activity may be attributed to the degradation caused by peroxisomal proteases as well as the photoinactivation of enzymes [25, 26]. It can be noted that the pretreatment with SA alleviated the inhibitory effects of Cd on CAT activity [5]. In other hand, APX activity was remarked increased with increasing $\mathrm{Cd}$ concentration compared with the control. This increase in APX activity in Cd-treated plants seems to be in response of increased accumulation of $\mathrm{H}_{2} \mathrm{O}_{2}$ [26]. The SA pretreatment was found to continuously increase the APX activity in Cd-stressed maize leaves. This result is in a good agreement with our previous study $[21,22]$. It is worthwhile to note that the dissimilar CAT and APX activities exhibited under both Cd stress and SA treatment may be due to the competition between APX and CAT on the same working substrate, $\mathrm{H}_{2} \mathrm{O}_{2}$, which shows higher activity with APX. This could be explained by the fact that if the detoxification of $\mathrm{H}_{2} \mathrm{O}_{2}$ is mainly occurred by APX, the CAT activity would be declined due to the lesser availability of $\mathrm{H}_{2} \mathrm{O}_{2}$ [26].

POD activity increase continuously with increasing $\mathrm{Cd}$ concentration. In contrast to what have been reported in sorghum leaves under Cd toxicity [22]. This increase in POD activity after $\mathrm{Cd}$ treatment indicates that $\mathrm{H}_{2} \mathrm{O}_{2}$ may further be produced by POD through oxidation of various molecules, such as $\mathrm{NAD}(\mathrm{P}) \mathrm{H}$ [23]. Moreover, the pretreatment with SA significantly enhanced POD activity in leaves of maize seedlings with or without Cd treatment.

It can also be noted that the treatment with $\mathrm{Cd}$ decreases ascorbate content in leaves of maize seedlings and thereby reducing $\mathrm{H}_{2} \mathrm{O}_{2}$ detoxification [27] and plant defense against oxidative stress [2]. The pretreatment with SA also significantly increased the ascorbate content. This is well agreed with our results reported earlier [28].

Cysteine content was significantly declined under $\mathrm{Cd}$ treatment. This may inhibit the synthesis of glutathione which acts as a putative ligand for metals in plant cells [28]. Generally, the adverse effects of Cd stress on cysteine content in leaves maize was partially or completely alleviated by soaking seeds in SA.

Proline content increased markedly in the Cd-treated plants. Enhanced proline accumulation in response to $\mathrm{Cd}$ toxicity has been earlier demonstrated in sorghum [22]. However, the pretreatment with SA before exposure to $\mathrm{Cd}$ decreased the stimulatory effect of $\mathrm{Cd}$ on proline accumulation. This noticeable decrease in proline content in wheat plants grown from SA-pretreated seeds indicates a particle recovery from Cd stress [29].

\section{Conclusion}

SA-induced alleviation of the negative effects of Cd toxicity may be attributed to the following reasons:

(i) SA allayed the $\mathrm{Cd}$-induced oxidative damages.

(ii) The lowering levels of $\mathrm{H}_{2} \mathrm{O}_{2}, \mathrm{MDA}$, electrolyte leakage and proline content of SA-pretreated plants in comparison with $\mathrm{Cd}$ exposed plants.

(iii) SA- altered activities of CAT, POD and APX plants treated with and without $\mathrm{Cd}$.

It is interesting to conclude that the adverse effects of $\mathrm{Cd}$ toxicity in enzymatic antioxidants involved in the oxidative defense mechanism in plants can be significantly alleviated by application of SA. 


\section{References}

[1] Gozubenli, H. 2010. Seed vigor of maize grown on the contaminated soils by cadmium. Asian J. Plant Sci. 9: 168-171.

[2] Msttes, J.M. 2000. Effects of antioxidant enzymes in the molecular control of reactive oxygen species toxicology. Toxicology 153: 83-104.

[3] Noctor, G. and Foyer, C.H. 1998. Ascorbate and glutathione: Keeping active oxygen under control. Ann. Rev. Plant Physiol. Plant Mol. Biol. 49: 249-279.

[4] Mishra, A. and Choudhuri, M.A. 1999. Effects of salicylic acid on heavy metal-induced membrane deterioration mediated by lipoxygenase in rice. Biol. Plant. 42: 409-415.

[5] Krantev, A., Yordanova, R., Janda, T., Szalai, G. and Popova, L. 2008. Treatment with salicylic acid decreases the effect of cadmium on photosynthesis in maize plants. J. Plant Physiol. 165: 920-931.

[6] Al-Hakimi, A.M.A. 2006. Counteraction of drought stress on soybean plants by seed soaking in salicylic acid. J. Bot. 2: 421-426.

[7] Arfan, M., Athar, H.R. and Ashraf, M. 2007. Does exogenous application of salicylic acid through the rooting medium modulate growth and photosynthetic capacity in two differently adapted spring wheat cultivars under salt stress?. J. Plant Physiol. 6: 685-694.

[8] Velikova, V., Yordanov, I. and Edreva, A. 2000. Oxidative stress and some antioxidant systems in acid rain treated bean plants, protective role of exogenous polyamines. Plant Sci. 151: 59-66.

[9] Madhava Rao, K.V. and Sresty, T.V.S. 2000. Antioxidative parameters in the seedlings of pigeon pea (Cajanus cajan $\mathrm{L}$. Millspaugh) in response to $\mathrm{Zn}$ and Ni stresses. Plant Sci. 157: 113-128.

[10] Rout, N.P. and Shaw, B.P. 2001. Salt tolerance in aquatic macrophytes: Possible involvement of the antioxidative enzymes. Plant Sci. 160: 415-423.

[11] Hassan, M.J., Shao, G.S. and Zhang, G.P. 2005. Influence of cadmium toxicity on growth and antioxidant enzyme activity in rice cultivars with different grain cadmium accumulation. J. Plant Nutr., 28: 1259-1270.

[12] Janda, T., Szalai, G., Tari, I. and Paldi, EO. 1999. Hydroponic treatment with salicylic acid decreases the effects of chilling injury in maize (Zea mays L.) plants. Planta 208: 175-180.

[13] Lowry, C.H., Rosebrought, N.J., Farr, A.L. and Randall, R.J. 1951. Protein measurement with the folin phenol reagent. J. Biol. Chem. 193 256-275.

[14] Kampfenkel, K., Van Montagu, M., and Inzé, D. 1994. Extraction and determination of ascorbate and dehydroascorbate from plant tissue. Ana. Biochem. 225: 165-167.

[15] Gaitonde, M.K. 1967. A spectrophotometric method for the direct determination of cysteine in the presence of other naturally occurring amino acids. Biochem. J. 104: 627- 633.

[16] Bates, L.S., Waldren, R.P. and Teare, R.P. 1973. Rapid determination of free proline for water-stress studies. Plant Soil 39: 205-207.

[17] Foyer, C.H. and Noctor, G. 2005. Oxidant and antioxidant signaling in plants: A reevaluation of the concept of oxidative stress in a physiological context. Plant Cell Environ. 28: 1056-1071.

[18] Kolupaev, Y.E., Oboznyi, A. I. and Shvidenko, N.V. 2013. Role of hydrogen peroxide generation of a signal inducing heat tolerance of wheat seedlings. Russ. J. Plant Physiol. 60: 221-229.

[19] Bestwick, C.S., Brown, I.R. and Mansfield, J.W. 1998. Localized changes in peroxidase activity accompany hydrogen peroxide generation during the level opment of a non-host hypersensitive reaction in lettuce. Plant Physiol. 118: 1067-1078.

[20] Romero-Puertas, M.C., Perazzolli. M., Zago, E.D. and Delledonne, M., Nitric oxide signaling functions in plant-pathogen interactions. Cell Microbiol. 6: 795-803.

[21] Ahmad, P., Nabi, G. and Ashraf, M. (2011). Cadmium-induced oxidative damage in mustard [Brassica juncea (L.) Czern. and Coss.] plants can be alleviated by salicylic acid. South Afri. J. Bot. 77: 36-44.

[22] Odeeni, S.A.S. 2012. Physiological and biochemical basis of cadmium toxicity in sorghum seedlings and its alleviation by salicylic acid application. Msc. Thesis, Fac. of Applied Sci. Taiz University Taiz Yemen, pp. 1-132.

[23] Ranieri, A., Castagna, A., Scebba, F., Careri, M., Zagnoni, I., Predieri, G., Pagliari, M. and Sanita di Toppi, L. 2005. Oxidation Stress and phytochelatin characterization in bread wheat exposed to cadmium excess. Plant Physiol. Biochem.43: 45-54.

[24] Belkhadi, A., Hediji, H., Abbes, Z., Nouairi, I., Barhoumi, Z., Zarrouk, M., Chaïbi, W. and Djebali, W. 2010. Effects of exogenous salicylic acid pretreatment on cadmium toxicity and leaf lipid content in Linum usitatissimum L.. Ecotoxicol. Environ. Saf. 73:1004-1011.

[25] Sandalio, L.M., Dalurzo, H.C., Gomez, M., Romero-Puertas, M.C. and del Rio, L.A. 2001. Cadmium induces changes in the growth and oxidative metabolism of pea plants. J. Exp. Bot. 52:2115-2126.

[26] Shekhawat, G.S., Verma, K., Jana, S., Singh, K., Teotia, P. and Prasad, A. 2010. In vitro biochemical evaluation of cadmium tolerance mechanism in callus and seedlings of Brassica juncea. Protoplasma 239: 31-38.

[27] Martinez-Penalver, A., Grana, E., Reigosa, M.J. and Sanchez-Moreiras, A.M. 2012. The early response of Arabidopsis thaliana to cadmium and copper-induced stress. Environ. Exp. Bot. 78: 1-9.

[28] Al-Hakimi, A.M.A., Molaaldoila, Y.A.A. and Odeeni, S.A.S. 2014. Effect of Salicylic acid on some biochemical changes in sorghum roots under cadmium stress. $7^{\text {th }}$ International Conference for the Development and Environment in the Arab world, March, 23-25.

[29] Moussa, H.R. and EL-Gamal, S.M. 2010. Effect of salicylic acid pretreatment on cadmium toxicity in wheat. Biol. Plant.54: 315-320. 